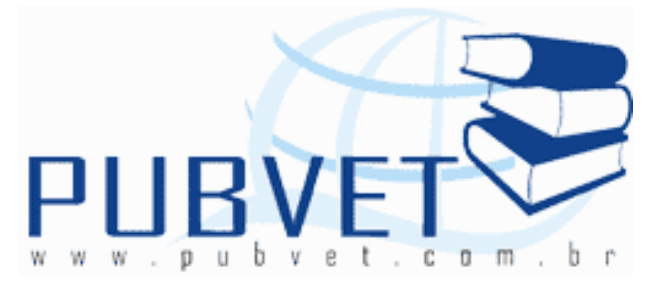

PUBVET, Publicações em Medicina Veterinária e Zootecnia.

\title{
Mixomatose em coelho doméstico criado como animal de estimação em Mato Grosso
}

Jaqueline Bruning Azevedo1, Glaucenyra Cecília Pinheiro Silva², Adriana Borsa2, Caroline Argenta Pescador ${ }^{3}$, Darci Lara Perecin Nociti3 , Adriano Jorge Possamai $^{4}$

${ }^{1}$ Graduanda em Medicina Veterinária, FAMEVZ-UFMT, Cuiabá. 2Doutoranda - Medicina veterinária preventiva-UNESP, Campus Jaboticabal. 3Doutora. Departamento de Clínica Médica Veterinária - FAMEVZ-UFMT, Cuiabá.

${ }^{4}$ Mestrando - Programa de pós-graduação em ciência animal-UFMT, Cuiabá.

\section{Resumo}

No ano de 2011, deu entrada no Hospital veterinário da Universidade Federal de Mato Grosso, um coelho com sinais clínicos sugestivos para mixomatose, com aspecto de "face leonina", com nódulos espalhados por todo o corpo e blefaroconjuntivite. Com o histórico de conviver com outros lagomorfos, cães e gatos. O animal veio a óbito e foi realizada a necropsia, macroscopicamente observou-se a blefaroconjuntivite purulenta bilateral, as pálpebras, pele da face, orelhas e região nasolabial apresentavam-se espessadas e com nódulos irregulares. No exame interno não foram observadas alterações. Microscopicamente, na pele observou-se a camada epidérmica esponjosa e a formação de pequenas áreas pustulares multifocais acentuadas e infiltrado 
AZEVEDO, J.B. et al. Mixomatose em coelho doméstico criado como animal de estimação em Mato Grosso. PUBVET, Londrina, V. 8, N. 7, Ed. 256, Art. 1694, Abril, 2014.

inflamatório supurativo na junção da epiderme com a derme. No pulmão visualizava-se edema difuso e acentuado, e congestão, fechando assim o diagnóstico para mixomatose.

Palavras-chave: lagomorfos, "face leonina", Cuiabá

\section{Myxomatosis in domestic rabbits keeping as pet in Mato Grosso state}

\section{Abstracts}

In 2011, was admitted to the Veterinary Hospital of the Federal University of MatoGrosso, a rabbit with clinical signs suggestive of myxomatosis, presenting a "leonine face" with nodes scattered throughout the body and blepharoconjunctivitis. With a history of living with other lagomorphs, dogs and cats. The animal died and an autopsy was performed, it was observed macroscopically blepharoconjunctivitis bilateral purulent, eyelids, facial skin, ears and nasolabial region presented with thickened and irregular nodules. On internal examination no changes were observed. Microscopically observed on the skin epidermal layer of the sponge and the formation of small areas marked multifocal pustular and suppurative inflammatory infiltrate at the junction of the epidermis, the dermis. Visualized in the lung is diffuse swelling and sharp, and congestion, thus closing the diagnostic myxomatosis

Keywords: lagomorphs, "leonine face", Cuiabá.

\section{INTRODUÇÃO}

A mixomatose é uma enfermidade de caráter sistêmico e de distribuição cosmopolita (FENNER, 1983). Pertencente ao gêneroLeporivirus,o vírus é responsável pela doença em lagomorfos domésticos e silvestres, tendo como principais sinais clínicos a cabeça com aspecto 'leonino', a blefaroconjuntivite, tumores subcutâneos eedemas, e microscopicamente apresenta-se com alterações epidérmicas e de derme, de degeneração e infiltrado inflamatório difuso(ARAGÃO, 1927; BRUNO, LOPES-JUNIOR, DEMARQUE, et al, 2004). 
AZEVEDO, J.B. et al. Mixomatose em coelho doméstico criado como animal de estimação em Mato Grosso. PUBVET, Londrina, V. 8, N. 7, Ed. 256, Art. 1694, Abril, 2014.

Levando ao surgimento dos primeiros sinais clínicos cinco dias após a infecção (MOSES, 1911). Na forma aguda, a morte do animal ocorre de dois a três dias após os primeiros sinais clínicos, podendo apresentar inanição visto que o animal perde a sua capacidade visual, não se movendo e não se alimentando, pode ocorrer também a obstrução das vias aéreas que pode ser motivada pelas infecções secundárias, principalmente por pasteurelose (BRUGUERE; PICOUX, 1991).Enfermidade presente em nosso continente, sua transmissão se da através do contato com animais infectados e veiculadores mecânicos, como os mosquitos(ARAGÃO, 1943).Segundo Lenner(2000), o Leporipoxvirus é pouco estudado, sem muito conhecimento sobre sua biologia molecular e sua história natural. Devido a esse aspecto objetivou-se relatar um caso de mixomatose em coelho atendido no Hospital Veterinário da Universidade Federal de Mato Grosso visto que trata-se de uma doença sistêmica e letal.

\section{MATERIAL E MÉTODOS}

Em20 de junho de 2011, deu entrada no Hospital Veterinário da Universidade Federal de Mato Grosso (HOVET-UFMT), um coelho macho, sem raça definida e com aproximadamente 3 anos de idade.Apresentava como sintomatologia: edema de face ("face leonina") e orelhas, nódulos espalhados por diversas partes do corpo, principalmente membros, pavilhão auricular e nariz. Apresentava também blefaroconjuntivite(figura1a). Segundo a proprietária, no dia 18 de junhoela observouno animal conjuntivite e edema na face.

Durante a anamnese, a proprietária informou que o mesmo convivia com outros lagomorfos, além de cães e gatos. A proprietária tinha seis coelhos em seu domicílio, criados como animais de estimação. Desse total, dois adoeceram de forma súbita e não tiveram auxilio veterinário, o terceiro encaminhado ao(HOVET-UFMT). Esses animais viviam em um local cimentado localizado dentro da propriedade e esta estava a aproximadamente 500 metros de uma área de preservação permanente. Todos eram criados juntos e recebiam, como fonte de alimentação, ração para gato e vegetais e nenhum dos animais 
recebeu algum tipo de vacina, aqueles que apresentavam sinais clínicos eram tratados com antibióticos. O animal veio a óbito na tarde do dia 21 do mesmo mês. No dia 29 de junho de 2011 foi realizada a necropsia.

\section{RESULTADOS}

No exame macroscópico externo, realizado durante a necropsia, foi observada a blefaroconjuntivite purulenta bilateral (fig.1B e 1C) As pálpebras, pele da face, orelhas e região nasolabial apresentavam-se espessadas e com nódulos irregulares (fig.2D) No exame interno não foram observadas alterações. No exame microscópico da pele observou-se a camada epidérmica esponjosae a formação de pequenas áreas pustulares multifocais acentuadas, também apresentavam acantose de forma moderada e com infiltrado inflamatório supurativo na junção da epiderme com a derme.Nesta ultima, foi observada a proliferação de colágeno entremeando as áreas de edema e um leve infiltrado inflamatório(Figura $1 \mathrm{E}$ e $1 \mathrm{~F}$ ). No intestino, fígado e rins não foram observadas alterações. No pulmão visualizava-se edema difuso e acentuado, e congestão, fechando assim o diagnóstico para mixomatose.

\section{DISCUSSÃO}

As descrições das lesões, tanto macro quanto microscopicamente, se assemelham aos relatos encontrados nas literaturas (ARAGÃO,1927; ARAGÃO, 1943; BRUNO et al, 2004). Como este animal vivia perto de uma área de preservação pode se sugerirque a transmissão do vírus possa ter ocorrido por vetores mecânicos como os mosquitos do gênero Aedes.Esse agente também pode ser transmitido por pulgas e carrapatos. O vírus do myxoma é bastante patogênico para o coelho e a sua transmissão de um animal para outro parece aumentar a virulência, levando o coelho à morte em até cinco dias (ARAGÃO, 1927).Já nas outras espécies não há relatos de sua importância patológica.Surtos em criações e cuniculturas não são observados com frequência em nosso Estado 


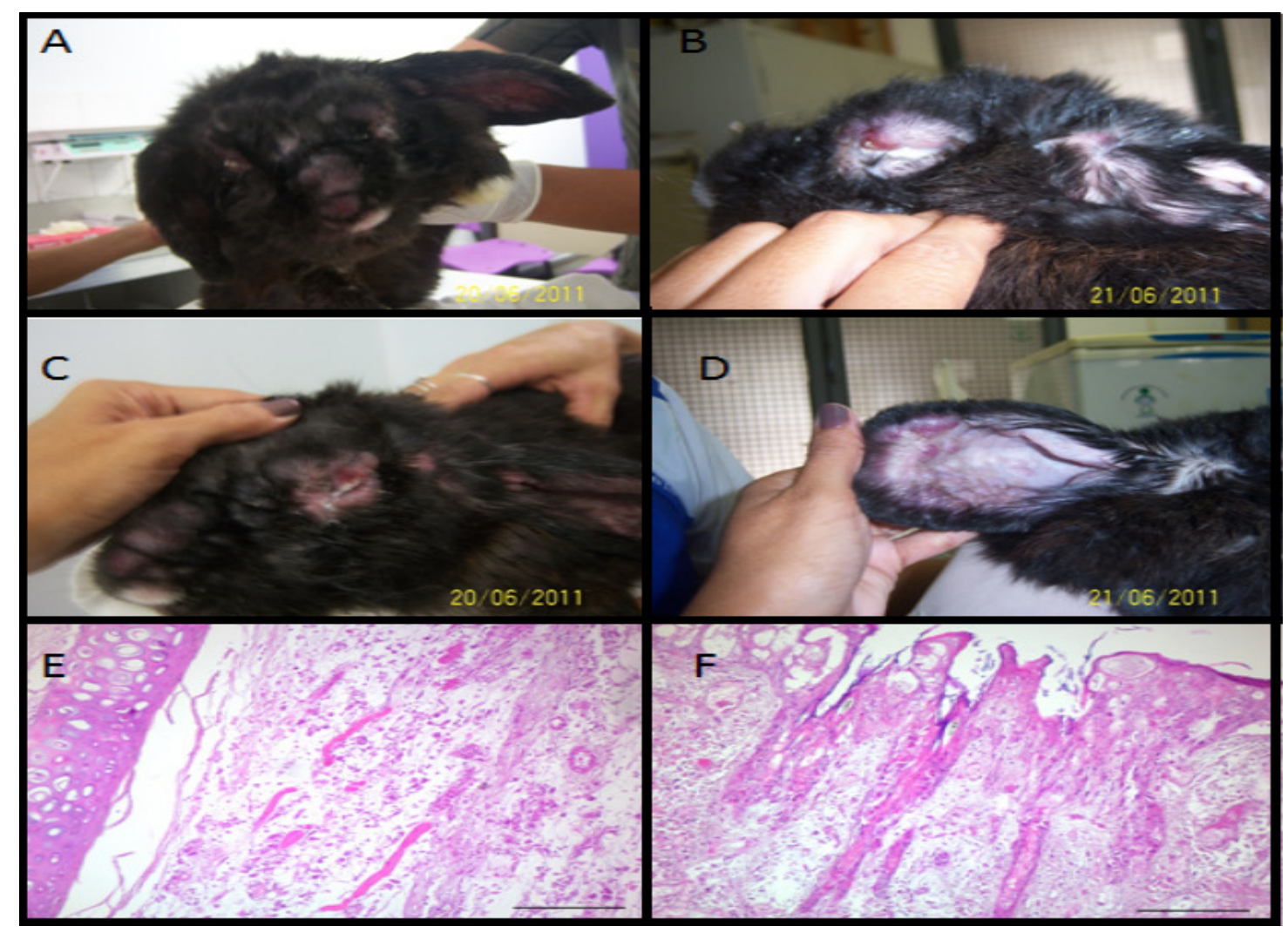

Figura 1: Coelho, mixomatose: Figura 1A: face leonina; Figura 1B:blefaroconjuntivite e secreção purulenta; Figura 1C: pálpebra e face com formações nodulares; Figura 1D: nódulos na região auricular; Figura 1E e $1 \mathrm{~F}$ :camada epidérmica esponjosa e a formação de áreas pustulares multifocais acentuadas, acantose moderada e infiltrado inflamatório supurativo na junção da epiderme com a derme, HE x100;

\section{CONCLUSÃO}

No estado de Mato Grosso não é comum relato de animais que apresentaram sinais clínicos sugestivos para mixomatose. Esse pode ter sido o primeiro caso relatado. $\mathrm{O}$ que se sabe é que o vírus está presente, visto que o diagnóstico foi fechado. Sendo assim, pode se gerar várias hipóteses sobre as formas comque esses animais tiveram contato com o agente e tudo leva a crer que o vírus esteja circulante nessa região peridomiciliar. 


\section{REFERÊNCIAS BIBLIOGRÁFICAS}

ARAGÃO, H.D.B. Myxomaofrabbits. Mem. Inst. Oswaldo Cruz 20, 237-247, 1927.

ARAGÃO, H.D.B. O virus do mixoma no coelho do mato (Sylvilagusminensus) sua transmissão pelos Aedes scapularis e aegypti. Mem. Inst. Oswaldo Cruz 38, 93-99, 1943.

BRUNO, S.F.; LOPES-JUNIOR, S.V.S.; DEMARQUE, K.C.;VIEIRA, T.B.; TORTELLY, R. Achados clínicos e anatomopatológicos em um surto de mixomatose no Rio de Janeiro (Relato de caso). Arq.Ciên. Vet. Zool. UNIPAR, p. 85-88, 2004.

FENNER,F.The Florey Lecture, 1983: Biological Control, as Exemplified by Smallpox Eradication and Myxomatosis. Proc. R. Soc. Lond. B, p 259-285 June 1983. Disponível em:rspb.royalsocietypublishing.org. Acessado em: 2 de maio de 2013.

J. BRUGUERE- PICOUX.Clínica y profilaxis de lamixomatosis higiene y patologia.UniversitatAutònoma de Barcelona. Conigliocoftura, 5: 41-47, 1991.

MOSES, A. O virus do mixoma dos coelhos. Mem. Instit. Oswaldo Cruz 3, 46-53, 1911.

SARAIVA, D.; BARROS, S.S.; SANTOS, M.N. Surto de mixomatose em Santa Maria. Ver. Centro Ciências Rurais. Volume 3, numero 1-4, p 71-80, 1973. 